\title{
Modifikasi Amilum Ganyong (Canna indica L.) dengan Metode Pregelatinasi Parsial untuk Eksipien Tablet Kempa Langsung
}

\author{
Modification of Purple Arrowroot (Canna indica L.) Starch by Partial \\ Pre-gelatinization Method for the Excipient of Direct Compressed Tablets
}

\author{
Deny Puriyani Azhary*, Rahma Zisca, Yanni Dhiani Mardhiani, Dhini Dwi Utami \\ Fakultas Farmasi, Universitas Bhakti Kencana, \\ Jl. Soekarno Hatta No.754, Bandung, Indonesia \\ *Corresponding author email: deny.puriyani@gmail.com
}

Received 12-9-2019 Accepted 11-12-2019 Available online 30-12-2019

\begin{abstract}
ABSTRAK
Amilum ganyong adalah biomaterial yang dapat digunakan dalam industri farmasi karena memiliki sifat fisikokimia yang menyerupai amilum singkong, yang telah umum digunakan untuk industri farmasi. Amilum ganyong alami memiliki sifat alir dan kompresibilitas yang kurang baik, yang sangat penting pada proses pengempaan tablet khususnya dalam formulasi tablet kempa langsung. Tujuan dari penelitian ini adalah modifikasi amilum ganyong alami sehingga dapat memperbaiki sifat alir dan kompresibilitasnya untuk eksipien tablet kempa langsung. Modifikasi dilakukan dengan cara pregelatinasi parsial pada suhu 50,55 , dan $60^{\circ} \mathrm{C}$, kemudian dilakukan evaluasi amilum ganyong sebelum dan sesudah modifikasi. Setelah itu dilakukan pembuatan tablet asetosal menggunakan eksipien amilum ganyong modifikasi serta evaluasi karakteristik tablet. Hasil evaluasi amilum menunjukkan bahwa amilum ganyong modifikasi memiliki sifat alir dan kompresibilitas yang lebih baik daripada amilum alami. Hasil uji Anova menunjukkan adanya perbedaan yang signifikan pada hasil evaluasi amilum alami dan modifikasi $(P<0,05)$. Modifikasi amilum pada suhu $60{ }^{\circ} \mathrm{C}$ menunjukkan hasil terbaik. Hasil evaluasi tablet menunjukkan bahwa tablet yang menggunakan amilum modifikasi memiliki karakteristik sesuai persyaratan tablet yang baik.
\end{abstract}

Kata kunci: amilum, eksipien, ganyong, pregelatinasi, tablet.

\begin{abstract}
Purple arrowroot starch is a potential biomaterial to be used in the pharmaceutical industry for its physicochemical properties resembling the commonly used The natural purple arrowroot starch has poor flow and compressibility, which are essential in the process of tablet compressing, especially in the direct compression tablets formulation. The purpose of this study was to modify natural purple arrowroot in order to improve its
\end{abstract}


flow and compressibility. Modifications were carried out by partial pre-gelatinization at temperatures of 50,55, and $60{ }^{\circ} \mathrm{C}$, respectively. The physical properties of purple arrowroot starch were evaluated before and after modification. The acetosal tablets were prepared using the modified purple arrowroot starch as the excipients, and the characters of the obtained tablets were subsequently evaluated. The results showed that the modified purple arrowroot starch had a significantly better flow and compressibility than that of natural one by ANOVA test $(P<0.05)$. Modification of starch at a temperature of $60^{\circ} \mathrm{C}$ produced the best results. The tablets with modified starch showed characteristics that met the requirements of the good tablets.

Key words: excipients, pregelatination, purple arrowroot starch, tablets.

\section{Pendahuluan}

Pada teknologi pembuatan tablet, selain zat aktif dibutuhkan pula bahan tambahan (eksipien) seperti bahan pengisi, pengikat, penghancur, pelicin, dan bahan-bahan lain sesuai dengan formulasi yang dikehendaki. Bahan penghancur merupakan salah satu eksipien yang berfungsi untuk menghancurkan tablet di dalam tubuh setelah digunakan, sehingga tablet dapat segera melepaskan bahan aktif obatnya, terlarut, dan selanjutnya dapat diabsorpsi oleh tubuh untuk menimbulkan efek yang dikehendaki (Hadisoewignyo dan Fudholi, 2013). Salah satu bahan penghancur yang sering digunakan dalam pembuatan tablet adalah amilum. Amilum yang sudah lazim digunakan sebagai bahan penghancur dalam pembuatan tablet yaitu amilum kentang dan jagung.

Salah satu tanaman penghasil amilum lainnya adalah ganyong (Canna indica L.). Umbi ganyong mengandung karbohidrat dalam jumlah yang cukup banyak, sehingga dapat digunakan sebagai penghasil amilum. Mengubah umbi menjadi tepung atau amilum akan meningkatkan nilainya dilihat dari segi sifat fungsional dan juga komposisi kimianya (Carolina dan Ilmi, 2016). Pemanfaatan ganyong di Indonesia masih tergolong rendah baik untuk industri pangan ataupun industri lainnya. Pembudidayaannya lebih terpusat di Kepulauan Jawa, salah satunya Jawa Timur yang mampu menghasilkan \pm 700 ton/tahun dengan harga jual yang rendah (Lucia, 2009). Amilum ganyong alami memiliki kekurangan di antaranya memiliki sifat alir dan kompresibilitas yang kurang baik sehingga tidak sesuai untuk digunakan sebagai eksipien tablet kempa langsung. Amilum ganyong alami yang digunakan sebagai eksipien tablet, menghasilkan tablet yang rapuh dengan kekerasan yang rendah dan waktu hancur cepat (Azhary et al., 2017). Salah satu cara untuk memperbaiki sifat amilum alami yang kurang baik, dengan melakukan modifikasi (Hauschild dan Picker, 2004). Modifikasi amilum yang paling sederhana adalah dengan cara pregelatinasi, yang dapat mengubah tampilan fisik amilum. Terdapat dua metode pregelatinasi yaitu pregelatinasi parsial dan pregelatinasi sempurna. 
Pregelatinasi sempurna dilakukan dengan cara pemanasan suspensi amilum di atas suhu gelatinasi, sedangkan pregelatinasi sebagian (parsial) dilakukan dengan cara pemanasan suspensi amilum di bawah suhu gelatinasi (Bertolini, 2010).

Amilum jagung yang dimodifikasi secara pregelatinasi parsial dapat dijadikan sebagai bahan penghancur tablet (Adedokun, 2011). Kebaruan penelitian adalah menggunakan amilum ganyong yang dimodifikasi secara pregelatinasi parsial, untuk eksipien bahan penghancur tablet kempa langsung.

\section{Metode Penelitian}

Isolasi Amilum Ganyong

Tanaman ganyong diperoleh dari perkebunan ganyong di daerah Pangalengan, Bandung, Jawa Barat. Kemudian dilakukan determinasi di Laboratorium Taksonomi Tumbuhan, Jurusan Biologi, Fakultas Matematika dan Ilmu Pengetahuan Alam, Universitas Padjadjaran Jatinangor, Sumedang.

Isolasi amilum ganyong dilakukan dengan cara umbi ganyong dikupas kulitnya, kemudian dicuci sampai bersih dengan air yang mengalir, lalu dikeringkan di bawah sinar matahari. Setelah kering umbi ganyong diparut hingga berubah tekstur seperti bubur encer. Selanjutnya hasil parutan umbi ganyong diperas dengan kain batis hingga tidak dapat diperas lagi. Ampas yang tersisa di kain batis dicuci lagi dengan air lalu diperas kembali. Pemerasan dilakukan berulang sampai air perasan terlihat jernih. Filtrat yang didapatkan diendapkan di wadah selama 24 jam. Setelah mengendap sempurna, cairan jernih di atasnya didekantasi sehingga diperoleh endapan amilum ganyong. Endapan amilum kemudian dicuci kembali dengan air hingga diperoleh endapan amilum yang berwarna putih dan bersih. Endapan amilum kemudian dikeringkan di lemari pengering dengan suhu $50{ }^{\circ} \mathrm{C}$ selama 24 jam. Setelah kering, amilum diayak dengan pengayak mesh no. 80 .

Modifikasi Amilum Ganyong

Amilum ganyong dimasukkan ke dalam gelas ukur dan ditambahkan akuades, kemudian dipanaskan hingga mencapai suhu $60{ }^{\circ} \mathrm{C}$ sambil diaduk dengan menggunakan alat magnetic stirrer. Suhu dijaga selama 15 menit hingga terbentuk massa kental. Massa kental tersebut dikeringkan di lemari pengering pada suhu $60{ }^{\circ} \mathrm{C}$ selama 24 jam. Setelah kering, amilum ganyong diayak dengan menggunakan ayakan mesh nomor 80 (Neelam, 2012).

Evaluasi Amilum Ganyong Alami dan Modifikasi

Evaluasi amilum meliputi identifikasi amilum, uji kadar air, laju alir, sudut diam, bobot jenis nyata, dan bobot jenis mampat. Evaluasi juga dilakukan dengan perhitungan kompresibilitas, Scanning Electron Microscope (SEM), dan difraksi sinar $X$ (XRD).

\section{Pencetakan Tablet}

Pembuatan tablet dilakukan dengan mencampurkan bahan aktif asetosal dengan semua bahan 
tambahan, kemudian dimasukkan ke dalam hopper mesin cetak lalu diatur kondisi mesin hingga tercapai bobot tablet $300 \mathrm{mg}$, dan tablet siap dicetak. Formula tablet dapat dilihat pada Tabel 1.

Tabel 1. Formulasi tablet

\begin{tabular}{lccccc}
\hline \multirow{2}{*}{ Nama Zat } & \multicolumn{5}{c}{ Formula Tablet (mg) } \\
\cline { 2 - 6 } & F 1 & F 2 & F 3 & F4 & F5 \\
\hline Asetosal & 80 & 80 & 80 & 80 & 80 \\
Avicel PH 102 & 184 & 184 & 184 & 184 & 184 \\
Amilum ganyong alami & 30 & - & - & - & - \\
Amilum ganyong modifikasi suhu $50^{\circ} \mathrm{C}$ & - & 30 & - & - & - \\
Amilum ganyong modifikasi suhu $55^{\circ} \mathrm{C}$ & - & - & 30 & - & - \\
Amilum ganyong modifikasi suhu $60^{\circ} \mathrm{C}$ & - & - & - & 30 & - \\
Starch $1500^{\circledR}$ & - & - & - & - & 30 \\
Mg stearat & 3 & 3 & 3 & 3 & 3 \\
Talkum & 3 & 3 & 3 & 3 & 3 \\
Bobot tablet & 300 & 300 & 300 & 300 & 300 \\
\hline
\end{tabular}

Keterangan: $\mathrm{F} 1=$ tablet dengan eksipien amilum ganyong alami, $\mathrm{F} 2=$ tablet dengan eksipien amilum ganyong modifikasi suhu $50^{\circ} \mathrm{C}, \mathrm{F} 3=$ tablet dengan eksipien amilum ganyong modifikasi suhu $55{ }^{\circ} \mathrm{C}, \mathrm{F} 4=$ tablet dengan eksipien amilum ganyong modifikasi suhu $60^{\circ} \mathrm{C}, \mathrm{F} 5=$ tablet dengan eksipien starch $1500^{\circledR}$.

\section{Evaluasi Tablet}

Evaluasi tablet meliputi, keragaman bobot, kekerasan, kerapuhan, dan waktu hancur. Uji kekerasan tablet dilakukan dengan alat hardness tester (Distec), dengan cara alat diset sesuai dengan diameter tablet dan jumlah tablet yang diuji. Saat tablet pecah, pada alat akan tertera kekerasan tablet yang dinyatakan dalam satuan kilogram (kg).

Pemeriksaan kerapuhan tablet dilakukan menggunakan alat friability and abrasion tester (Tipe TFT-2). Sebanyak 10 tablet diambil, kemudian tablet dijepit dengan pinset, dibersihkan dengan hati-hati dengan kuas, kemudian ditimbang. Tablet tersebut dimasukkan ke dalam alat penguji friability tester and abrasion tester dengan putaran sebanyak 100 putaran per menit selama 4 menit. Kemudian tablet dikeluarkan dari alat dan dibersihkan dengan kuas secara hati-hati. Tablet ditimbang kembali dan dihitung persentase kekurangan bobotnya. Nilai kerapuhan tablet yang diperbolehkan adalah $<1 \%$.

Pemeriksaan waktu hancur tablet dilakukan dengan alat disintegration tester (Precisa Tipe XM 60). Tablet yang akan diperiksa dimasukkan satu per satu ke dalam 
tabung basket disusul dengan cakram penuntun. Basket dimasukkan ke dalam beaker glass berukuran satu liter yang berisikan air suling dengan suhu $37 \pm 2{ }^{\circ} \mathrm{C}$ sebagai media. Alat dihentikan setelah tablet hancur sempurna. Waktu yang dibutuhkan akan tertera pada alat. Persyaratan untuk waktu yang dibutuhkan tidak lebih dari 15 menit (Kemenkes RI, 2014).

\section{Analisis Statistik}

Metode analisis yang digunakan adalah one-way Anova untuk mengetahui perlakuan yang memberikan pengaruh nyata terhadap parameter yang diinginkan pada tingkat kepercayaan $95 \%(\alpha=0,05)$.

\section{Hasil dan Pembahasan}

Amilum ganyong alami yang dihasilkan berupa serbuk halus, berwarna putih, dan tidak berbau dengan rendemen $10,43 \%$. Sedangkan amilum ganyong modifikasi yang dihasilkan berupa serbuk berwarna putih dan tidak berbau dengan rendemen $79,0 \%$.

Evaluasi Amilum Ganyong Alami dan Modifikasi

Hasil identifikasi amilum menunjukkan terjadi pembentukan warna biru gelap yang spesifik setelah ditetesi larutan iodin. Amilum dan iodin akan saling berinteraksi yang akhirnya terjadi kompleks amilum-iodin.

Hasil evaluasi amilum ganyong alami dan modifikasi yang meliputi laju alir, sudut diam, bobot jenis nyata, bobot jenis mampat dan kadar air dapat dilihat pada Tabel 2. Hasil pemeriksaan kadar air dengan alat moisture analyzer
(Mettler Toledo Tipe HE53) menunjukkan kadar air amilum ganyong alami $11,28 \%$ tidak sesuai persyaratan, sedangkan amilum modifikasi diperoleh harga 5,25; 4,67; dan 3,29\% sesuai persyaratan. Penurunan kadar air kemungkinan diakibatkan adanya proses pemanasan saat modifikasi amilum. Hal ini terbukti dengan sifat alir granul yang baik dan tidak lengket pada saat dilakukan pengempaan menjadi tablet dan mudah dikeluarkan dari ruang cetak.

Tabel 2 terlihat bahwa amilum ganyong alami membentuk sudut istirahat yang sangat besar yaitu $61,18^{\circ}$, sedangkan amilum ganyong modifikasi suhu 50,55 , dan $60^{\circ} \mathrm{C}$ masing-masing memiliki sudut istirahat 42,$69 ; 36,25$; dan $32,24^{\circ}$. Modifikasi suhu $55{ }^{\circ} \mathrm{C}$ dan $60{ }^{\circ} \mathrm{C}$ menghasilkan amilum dengan sudut istirahat yang sesuai persyaratan yaitu $25^{\circ}-40^{\circ}$.

Hasil pengujian laju alir dengan alat Granule Flow Tester (GFT-AU 100) terlihat bahwa amilum ganyong alami memiliki laju alir yang buruk yaitu 4,85 gram/detik, tidak sesuai persyaratan laju alir yang baik yaitu $>5$ gram/detik. Hal ini dikarenakan kadar air pada amilum ganyong yang tinggi $(11,28 \%)$ sehingga amilum tidak dapat mengalir dengan baik. Sedangkan pada amilum ganyong modifikasi ketiga suhu menunjukkan hasil laju alir yang baik. Modifikasi pregelatinasi dengan pemanasan menyebabkan penurunan derajat sudut istirahat amilum dan laju alir lebih cepat. Berdasarkan hasil pengujian Anova menunjukkan bahwa laju alir tiap sampel 
memberikan hasil yang berbeda sedangkan Starch $1500^{\circledR}$ sebesar $6,94 \%$. signifikan $(P<0,05)$. Semakin kecil persen kompresibilitas,

Dari hasil pemeriksaan persen maka semakin baik kecepatan alirnya, kompresibilitas diperoleh harga untuk karena volume rongga udara semakin amilum ganyong alami sebesar $8,33 \%$. Amilum ganyong modifikasi masingmasing memiliki persen kompresibilitas sebesar 8,$22 ; \quad 9,59 ;$ dan $7,04 \%$; kecil. Hasil evaluasi amilum ganyong alami dan modifikasi (Tabel 2) menunjukkan bahwa modifikasi pada suhu $60^{\circ} \mathrm{C}$ menunjukkan hasil terbaik.

Tabel 2. Hasil evaluasi amilum ganyong alami dan modifikasi

\begin{tabular}{|c|c|c|c|c|c|}
\hline \multirow{2}{*}{ Evaluasi } & \multirow{2}{*}{$\begin{array}{c}\text { Amilum Ganyong } \\
\text { Alami }\end{array}$} & \multicolumn{3}{|c|}{ Amilum Ganyong Modifikasi } & \multirow{2}{*}{$\begin{array}{l}\text { Starch } \\
1500^{\oplus *}\end{array}$} \\
\hline & & Suhu $50^{\circ} \mathrm{C}$ & Suhu $55^{\circ} \mathrm{C}$ & Suhu $60^{\circ} \mathrm{C}$ & \\
\hline Laju Alir (g/det) & $4,82 \pm 0,25$ & $6,45 \pm 0,40$ & $7,13 \pm 0,37$ & $9,24 \pm 0,71$ & $12,85 \pm 0,45$ \\
\hline Sudut Istirahat $\left({ }^{\circ}\right)$ & $62,20 \pm 0,67$ & $42,69 \pm 0,85$ & $36,25 \pm 0,67$ & $32,24 \pm 0,90$ & $21,91 \pm 0,27$ \\
\hline $\begin{array}{l}\text { Bobot Jenis Nyata } \\
\qquad(\mathrm{g} / \mathrm{mL})^{* *}\end{array}$ & 0,66 & 0,67 & 0,66 & 0,66 & 0,67 \\
\hline $\begin{array}{c}\text { Bobot Jenis } \\
\text { Mampat }(g / m L)^{* *}\end{array}$ & 0,72 & 0,73 & 0,73 & 0,71 & 0,72 \\
\hline Kadar Air (\%) & $11,28 \pm 0,00$ & $5,25 \pm 0,00$ & $4,67 \pm 0,00$ & $3,29 \pm 0,00$ & $1,22 \pm 0,00$ \\
\hline
\end{tabular}

Foto SEM menunjukkan bahwa amilum ganyong alami berukuran 20-25 $\mu \mathrm{m}$ dengan susunan yang tunggal dan tidak bergerombol. Sedangkan amilum ganyong pregelatinasi suhu $60{ }^{\circ} \mathrm{C}$ menunjukkan ukuran partikel yang lebih besar yaitu 25-30 $\mu \mathrm{m}$ dan memiliki susunan bergerombol. Susunan amilum yang bergerombol diakibatkan adanya perlakuan pemanasan dan penambahan air sehingga mendekati proses gelatinasi amilum. Foto SEM dapat dilihat pada Gambar 1.

Difraktogram XRD menunjukkan puncak kristal amilum ganyong alami yang paling kuat berada pada $2 \theta 16,76^{\circ}$ dan amilum ganyong modifikasi suhu 60 ${ }^{\circ} \mathrm{C}$, puncak yang paling kuat berada pada $2 \theta 17^{\circ}$. Setelah mengalami proses modifikasi, pola kristalinitas amilum ganyong tidak mengalami perubahan. Difraktogram XRD tercantum pada Gambar 2.

\section{Evaluasi Tablet}

Hasil evaluasi tablet dapat dilihat pada Tabel 3, menunjukkan semua formula memenuhi persyaratan evaluasi keragaman bobot. Hasil pemeriksaan kekerasan tablet (Tabel 3) menunjukkan tablet dengan eksipien amilum ganyong alami memiliki kekerasan yang lebih rendah dibandingkan tablet dengan amilum ganyong modifikasi. Hal ini menunjukkan bahwa amilum ganyong yang dimodifikasi secara pregelatinasi parsial mempunyai daya kohesifitas yang baik. Gaya kohesif ini akan mempercepat proses konsolidasi, sehingga saat diberi 
tekanan pada waktu pencetakan tablet akan menghasilkan tablet yang keras. Berdasarkan hasil pengujian Anova menunjukkan bahwa nilai kekerasan tablet dari ketiga formula memberikan hasil yang berbeda signifikan $(P<0,05)$. Perbedaan eksipien yang digunakan menyebabkan perbedaan kekerasan pada tablet.

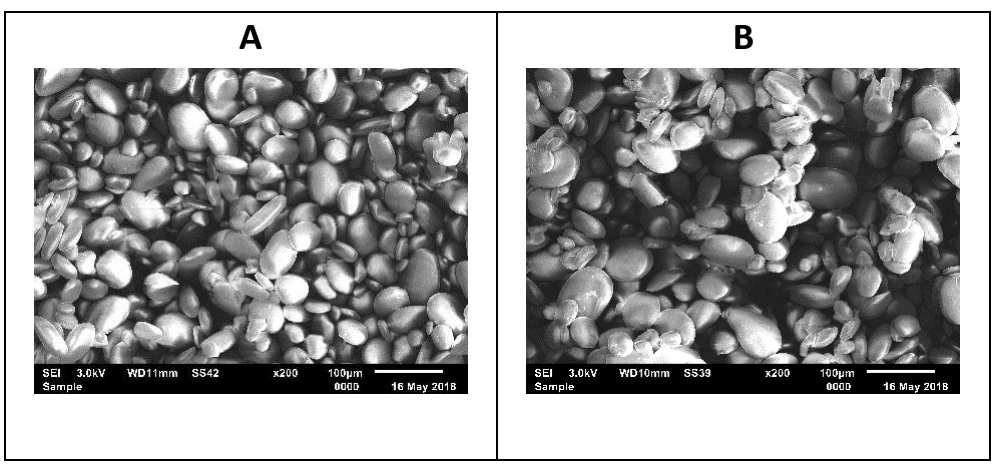

Gambar 1. Foto SEM A) amilum ganyong alami, B) amilum ganyong modifikasi.

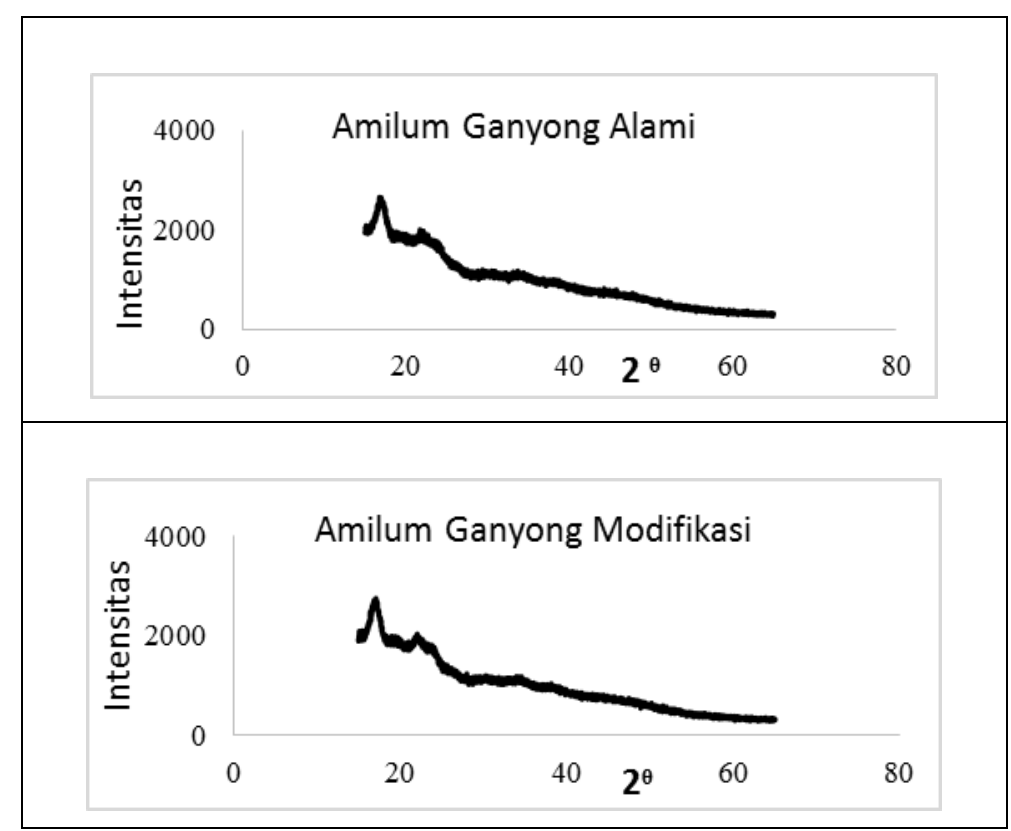

Gambar 2. Difraktogram XRD. 
Tabel 3. Hasil evaluasi tablet

\begin{tabular}{cccccc}
\hline Evaluasi & F1 & F2 & F3 & F4 & F5 \\
\hline Keragaman bobot & Memenuhi & Memenuhi & Memenuhi & Memenuhi & Memenuhi \\
& syarat* & syarat* & syarat* & syarat* & syarat* \\
Kekerasan (kg) & $5,40 \pm 0,12$ & $5,80 \pm 0,21$ & $6,70 \pm 0,29$ & $6,50 \pm 0,20$ & $6,90 \pm 0,12$ \\
Kerapuhan (\%) & $0,80 \pm 0,00$ & $0,28 \pm 0,00$ & $0,13 \pm 0,00$ & $0,34 \pm 0,00$ & $0,29 \pm 0,00$ \\
Waktu hancur (menit) & $2,29 \pm 0,01$ & $1,27 \pm 0,02$ & $1,25 \pm 0,03$ & $1,19 \pm 0,01$ & $1,09 \pm 0,04$ \\
\hline
\end{tabular}

Keterangan: * =Farmakope Indonesia edisi V, F1=tablet dengan eksipien amilum ganyong alami, F2=tablet dengan eksipien amilum ganyong modifikasi suhu $50{ }^{\circ} \mathrm{C}, \mathrm{F} 3=$ tablet dengan eksipien amilum ganyong modifikasi suhu $55{ }^{\circ} \mathrm{C}$, F4=tablet dengan eksipien amilum ganyong modifikasi suhu $60^{\circ} \mathrm{C}, \mathrm{F} 5=$ tablet dengan eksipien starch $1500^{\circledR}$.

Hasil pengujian kerapuhan dari masing-masing formula menunjukkan bahwa kerapuhan tablet berbanding terbalik dengan kekerasannya. Hal ini dapat dilihat dari semakin kuat daya ikat tablet, maka semakin kecil nilai kerapuhannya.

Hasil pemeriksaan waktu hancur menunjukkan semua tablet memiliki waktu hancur yang memenuhi persyaratan yaitu kurang dari 15 menit. Hal ini sesuai dengan sifat amilum yang memiliki sifat pengembangan yang baik sebagai disintegran.

\section{Simpulan}

secara pregelatinasi parsial dapat memperbaiki laju alir dan kompresibilitasnya. Tablet yang menggunakan eksipien amilum ganyong modifikasi memiliki waktu hancur yang lebih cepat daripada tablet dengan eksipien amilum ganyong alami.

\section{Ucapan Terima Kasih}

Penulis menghaturkan terima kasih yang sebesar-besarnya kepada
Kemenristek Dikti yang telah memberikan dana untuk terlaksananya penelitian ini.

\section{Daftar Pustaka}

Adedokun, M.O. dan Itiola, O.A. 2011. Disintegrant activities of natural and pregelatinized trifoliate yams, rice and corn starches in paracetamol tablets. Journal of Applied Pharmaceutical Science, 1(10):200-206.

Azhary, D.P., Zaelani, D., Lestari, T. 2017. Penggunaan pati ganyong (Canna edulis) sebagai disintegran pada pembuatan tablet asam folat dengan metode cetak langsung. Jurnal Farmasi Galenika, 4:20-23.

Bertolini, A. 2010. Starches Characterization, Properties, and Applications. Boca Raton: CRC Press.

Carolina, A., IImi, F.N. 2016. Production of Indonesian Canna edulis type IV resistant starch through acetylation modification. International Food Research Journal, 23(2):491-497. 
Hadisoewignyo, L. dan Fudholi, A. 2013. Sediaan Solida. Yogyakarta: Pustaka Pelajar.

Hauschild, K. dan Picker, K.M. 2004. Evaluation of a new coprocessed compound based on lactose and maize starch for tablet formulation. AAPS PharmSci, 6(2):112.

Kemenkes, RI. 2014 Farmakope Indonesia. Edisi V. Jakarta: Kementerian Kesehatan RI.
Lucia, T.P. 2009. Pemanfaatan pati ganyong (Canna edulis) pada pembuatan mie segar sebagai upaya penganerakaragaman pangan non beras. Media Pendidikan, Gizi dan Kuliner.; 1(1):1-6.

Neelam, K., Vijay, S., Lalit, S. 2012. Various techniques for the modification of starch and the applications of its derivatives. International Research journal of Pharmacy, 3(5):25-31. 